PHYSICAL REVIEW D 94, 099907(E) (2016)

\title{
Editorial Note: Models for small-scale structure on cosmic strings. II. Scaling and its stability \\ [Phys. Rev. D 94, 096005 (2016)]
}

J. P. P. Vieira, C. J. A. P. Martins, and E. P. S. Shellard

(Received 23 November 2016; published 30 November 2016)

DOI: $10.1103 /$ PhysRevD.94.099907

This paper was inadvertently published online on 11 November 2016 in the wrong issue of the journal (Issue 9: D1 instead of Issue 10: D15). This Note is being published in Issue 10 to call the article to the attention of interested readers. We regret the error. 